IZA DP No. 6852

The Impact of Divorce on Return-Migration of Family Migrants

Govert E. Bijwaard

Stijn van Doeselaar

September 2012

Forschungsinstitut zur Zukunft der Arbeit Institute for the Study of Labor 


\title{
The Impact of Divorce on Return-Migration of Family Migrants
}

\author{
Govert E. Bijwaard \\ Netherlands Interdisciplinary Demographic Institute (NIDI) \\ and IZA \\ Stijn van Doeselaar \\ Tilburg University
}
Discussion Paper No. 6852
September 2012

\author{
IZA \\ P.O. Box 7240 \\ 53072 Bonn \\ Germany \\ Phone: +49-228-3894-0 \\ Fax: +49-228-3894-180 \\ E-mail: iza@iza.org
}

\begin{abstract}
Any opinions expressed here are those of the author(s) and not those of IZA. Research published in this series may include views on policy, but the institute itself takes no institutional policy positions.

The Institute for the Study of Labor (IZA) in Bonn is a local and virtual international research center and a place of communication between science, politics and business. IZA is an independent nonprofit organization supported by Deutsche Post Foundation. The center is associated with the University of Bonn and offers a stimulating research environment through its international network, workshops and conferences, data service, project support, research visits and doctoral program. IZA engages in (i) original and internationally competitive research in all fields of labor economics, (ii) development of policy concepts, and (iii) dissemination of research results and concepts to the interested public.
\end{abstract}

IZA Discussion Papers often represent preliminary work and are circulated to encourage discussion. Citation of such a paper should account for its provisional character. A revised version may be available directly from the author. 


\section{ABSTRACT}

\section{The Impact of Divorce on Return-Migration of Family Migrants*}

Many migrants have non-labour motives to migrate and they differ substantially in their migration behaviour. Family migrants main migration motive is to join their future spouse. Thus, when their relation breaks down this influences their return decision. Using administrative panel data on the entire population of recent family immigrants to The Netherlands, we estimate the effect of a divorce on the hazard of leaving The Netherlands using the "timing-of-events" model. The model allows for correlated unobserved heterogeneity across the migration and the divorce processes. The family migrants are divided into three groups based on the Human Development Index (HDI) of their country of birth. We find that divorce has a large impact on the return of family migrants from less developed countries and less on the return of family migrants from developed countries. Young migrants with low income are influenced most by a divorce. We find some evidence of marriage for convenience for migrants from less developed countries. The impacts are quantified by graphing the impact of the timing of divorce on the return probability.

JEL Classification: J12, F22, C41

Keywords: temporary migration, timing of events method, marital status dynamics

Corresponding author:

Govert E. Bijwaard

Netherlands Interdisciplinary Demographic Institute (NIDI)

PO Box 11650

NL-2502 AR The Hague

The Netherlands

E-mail: bijwaard@nidi.nl

\footnotetext{
Financial support from the NORFACE research programme on Migration in Europe - Social, Economic, Cultural and Policy Dynamics is gratefully acknowledged. We thank Statistics Netherlands, Ruben van Gaalen in particular, for data support. We thank Arthur van Soest and Jaap Abbring for helpfull comments.

This research is based on van Doeselaar's Master thesis in Econometrics at Tilburg University.
} 


\section{Introduction}

International migration and the integration of migrants are among the most urgent social, economic and political issues in Europe today. In assessing the impact of migration and integration policies it is often overlooked that many migrants return to their home country or move on to a third country after a short period. The level of return migration has been high for both the US and in many European countries. Jasso and Rosenzweig (1982) report that between twenty and fifty percent of legal immigrants re-emigrated from US in the 1970s. Bijwaard (2010) reports return probabilities within five years between $25 \%$ and $50 \%$, depending on the migration motive, for migrants entering the Netherlands in 1995-2003. Similar numbers have been found for other Western European countries, see e.g. Edin et al. (2000) for Sweden, Jensen and Pedersen (2007) for Denmark and, Dustmann (1995) for Germany. Despite the knowledge that many migrations are temporary the majority of the literature on migration still (implicitly) assumes migrations are permanent. When many migrations are temporary and the migrants that re-migrate are more successful then the migrants that remain in the country, then the recruitment or selection of migrants is only part of the issue. We need to know who re-migrates and why, and who stays and why.

The main focus in the economics literature on migration has been on the behaviour of labour migrants, see a.o. Borjas (1999). However, many migrants have non-labour related motives to migrate ( $75 \%$ of recent migrants to the Netherlands) and other migrant groups substantially differ in their propensity to leave (see Bijwaard (2010)). Family migration (both family formation and family reunification) is a very important migration motive. Still only a few studies, with access to information on individual data on migrants' entry status, have looked at family migrants to the US, Jasso and Rosenzweig (1995), to Canada, Aydemir (2011), to Australia, Miller (1999), to Spain, Rodriguez-Planas and Vegas (2011) and to the Netherlands, Bijwaard (2010). These family migrants are generally less mobile than labour migrants. However, a marriage can break down and this may influence migration behaviour, because then the initial reason to migrate no longer validates a reason to stay. Little is known on how a divorce of a family migrant affects her/his decision to re-migrate. This paper will fill that gap, by analysing the relation between marriage and migration dynamics of recent family migrants to the Netherlands. We identify the effect of divorce on the return intensity of those migrants. We also discuss how this effect varies by the duration of the divorce spell and how it changes with observed migrant characteristics. The failure of the empirical literature to address these issues arises from a combination of methodological challenges and severe limitations of the data usually encountered in migration analysis.

We address these novel questions using a unique administrative panel for the entire population of recent immigrants to the Netherlands covering the years 1999-2007. This Dutch immigrant register is based on the legal requirement for immigrants to register with the authorities upon arrival. A feature of our data is the administrative report in the immigrant register (consistent with the visa status at entry) of the immigration motive. This enables us to focus explicitly and exclusively on 100,392 family immigrants ( $40 \%$ of all recent (non Dutch) migrants). The data contain information on the (day-exact) timing of migration moves to and from the Netherlands and on the timing of marriage dissolutions and formations (while the migrant is registered in the Netherlands). Several other official registers are linked by Statistics Netherlands to this immigrant register, such as the social benefit and the income register (used by the tax authorities). The size of our data allows us to estimate our models separately for distinct immigrant groups defined in terms of the human development index of their country of birth.

While modern duration analysis (see e.g. Van den Berg (2001) for a survey) is widely applied in labour economics, the limitations of available data have prevented its widescale adoption in migration studies. Among the exceptions is, for instance, Aydemir and Robinson (2008) who estimate proportional hazard models for outmigration on Canadian administrative data. We go beyond estimating such a model not only by allowing for unobserved heterogeneity in the migration process, but we also 
consider the divorce process jointly, for which unobservable heterogeneity is permitted to be correlated with that of the migration process. In particular, we estimate the effects of the timing of divorce on the hazard to re-migrate using the "timing-of-events" method (Abbring and van den Berg (2003)). At the same time, we control for the correlated effects that arise from the correlation between unobservables in the migration and divorce process (ignoring these, we show, would result in substantial endogeneity biases).

The outline of the paper is as follows. In Section 2 we discuss briefly the related literature. The econometric model is set out in detail in Section 3. In particular, we specify the divorce and the migration processes, and elucidate the role of unobservable heterogeneity. We also address the assumptions needed to allow for a causal interpretation of the estimated effect of divorce. The data are described in Section 4, and the empirical results are presented in Section 5. The last section concludes and the appendix we provides some additional information on the data used.

\section{Conceptual framework}

An important contribution to the theoretical explanations of return emigration of immigrants is provided by Borjas and Bratsberg (1996). They attribute return migration to an optimal residential plan over the life cycle where immigrants return to source countries due to the realization of a savings goal or due to erroneous information about economic opportunities in the host country. Other theories attribute return migration to region-specific preferences (Hill 1987; Dustmann and Weiss 2007), higher purchasing power of host currency in source countries (Dustmann and Weiss 2007) or to greater returns for human capital acquired in the host country (Borjas and Bratsberg 1996; Dustmann and Weiss 2007).

A problem with most of these explanations of return migration is that family migrants have mainly non-economic migration motives. This is illustrated by the fact that only $3 \%$ of the family migrants to the Netherlands are employed at entry ${ }^{1}$, and five years after entry this figure is still below $50 \%$. It is save to assume that those migrants mainly migrate to live together with their (future) spouse, at least initially. Thus, their personal economic situation in the host seems less important than their relationship in explaining their return. Return migration may therefore be the result of a change in marital status. If the relationship of the family migrant were to break up, whether or not children have been born, one or both partners would be likely to move. This move could be to local, regional or international.

Gibson and McKenzie (2011) find that family and lifestyle have a major impact on return decisions. Contrary to labour migrants, the majority of family migrants are female. It is therefore important to emphasize the gender difference in motivations for family migration. Migration of a household usually benefits the man's career. Women are less likely to be employed, have lower income following a migration as a couple, Boyle et al. (2001). For a female spouse the cost (psychological difficulties, uncertainty) of moving may be higher and, therefore, her preference for the source country might be higher, Flowerdew and Al-Hamad (2004). Then, after a divorce, a woman looses her motivation to stay in the host and this would naturally lead to return migration, Nivalainen (2004). Of course, women might also benefit from the better opportunities in the host, especially for women from less developed countries.

It is often found that migration leads to higher divorce rates, Boyle et al. (2008). In a study concerning Puerto Rican women Sandell (1977) has shown that those who had migrated to the US were more prone to divorce than the non-migrants, even after controlling for explanatory variables. One reason for this is that due to less social control in the host women feel more able to end their relationship. This would lead to less return migration after divorce.

Factors that influence the migration decision also influence the union dissolution decision. The

\footnotetext{
${ }^{1}$ In most cases this is also prohibited by law.
} 
independence hypothesis suggests that women with higher wages have less to gain from marriage and, therefore, may have higher divorce rates, Becker et al. (1977). Higher wages also imply the migrant has (used) better opportunities in the host and a divorce has less impact on the financial position of the woman. Children both discourages union dissolution and migration. Other demographic factors expected to influence separation and return migration rates include the duration of the union (duration in the country), religion and, the age at union formation (entry into the country). Religion has a negative effect on union dissolution and as a proxy for cultural distance to the secular Dutch society it influences the ease to assimilate.

Even in our modern society with easy transportation and contact facilities the distance to the source country still influences the likelihood of (return)-migration. Migrants from further away usually differ more in cultural norms and gender roles and, therefore, find it harder to assimilate into the host society. But return migration also involves higher costs when the distance is greater.

It is still possible that a substantial portion of the family migrants to the Netherlands come for economic reasons. By marrying a Dutch they might gain the opportunity to stay in the country (after three years of legal marriage). For such a marriage of convenience the effect of a divorce on return is high when the divorce occurs before the family migrant has gained an individual living permission and the effect is low when the divorce occurs later. For such migrants a divorce is more likely, especially after the official period of required legal marriage has passed, Hill (2004).

\section{Econometric Model}

We are interested in the effect of divorce on the return migration hazard of immigrants, so the outcome variable of interest is the time spent in the Netherlands. For both the migration and the divorce process the timing of the transitions and the time between transitions is crucial. In a duration model the timing of a particular event is usually modeled in terms of the associated hazard. A hazard model is invariant to right-censoring, i.e. the timing of the transition is unknown because the process continue to run beyond the observation window. Another reason to apply hazard models is that many relevant characteristics of the migrant, like for example income, may change over time. In hazard models it is straightforward to incorporate such time-varying variables. We follow common practice in duration analysis and use a proportional hazard $(\mathrm{PH})$ model, which expresses the hazard as the product of a baseline hazard, which is a function of time alone and common to all individuals, and a covariate function which accelerates or decelerates exits. The baseline hazard captures the effect of the assimilation of migrants into the host country on the return hazard. The longer they stay, the more they adapt to the culture and the more they get detached from the source country. To accommodate unobserved heterogeneity (see e.g. Van den Berg (2001) for a discussion of the importance of this), the mixed proportional hazard model (MPH) extends the $\mathrm{PH}$ model by multiplying it by a time-invariant person-specific random effect.

The empirical challenge arises from the potential correlation between the divorce process and the migration process which, if present and ignored, confounds the effect of divorce on return. We address this endogeneity issue by allowing for correlated unobservable heterogeneity. This provides us the opportunity to distinguish the direct impact of divorce from the correlation that can arise from the correlation between the unobserved heterogeneity terms (stemming from e.g. dynamic sorting). We also present the identification assumptions under which we have a causal interpretation of the effect of divorce on the return intensity.

\subsection{Divorce process and the return hazard}

Generically, let $T$ denote the random time since first entry into the Netherlands that a particular event takes place. In particular, $T_{m}$ is the time the immigrant leaves the host country in order to return to the source country, $T_{s}$ is the time a marriage spell ends in the host country. 


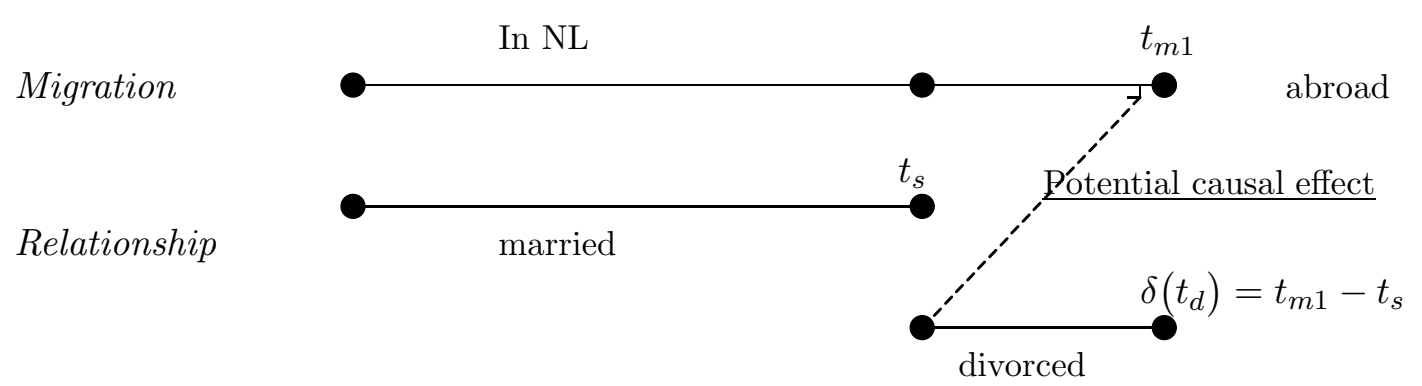

Figure 1: Migration and marriage dynamics

In Figure 1 we depict the marriage and migration duration of one arbitrary migrant. In accordance with our data definitions of Section 4, the migrant is married at the moment (s)he enters the country. The length of the marriage spell (in the Netherlands) is $\delta\left(t_{s}\right)=t_{s}$. She remains in the country divorced until time $t_{m 1}$. It is unknown whether the migrant remains divorced after leaving the country. We do know that her divorce spell in the Netherlands has lasted for $\delta\left(t_{d}\right)=t_{m 1}-t_{s}$. Thus, this migrant experiences an adverse shock (divorce) in her life that might induce her to leave. We seek to determine the effect of such a shock in terms of its incidences and its duration, on the duration of the migration spell.

We have two possible transitions: divorce and return migration. The conditional hazard for the marriage spell to end in divorce follows a mixed proportional hazard model:

$$
\theta_{s}\left(t \mid x_{s}(t), v_{s}\right)=v_{s} \lambda_{s}(t) \exp \left(x_{s}(t) \beta_{x}^{s}\right)
$$

with baseline hazard $\lambda_{s}$, unobserved time-invariant characteristics $v_{s}$, and observed time-varying characteristics $x_{s}$. We also define the associated time-varying indicator $I_{d}(t)$ which takes value one if the migrant is divorced at time $t$.

We allow $T_{m}$ and $T_{s}$ to be correlated through unobservable heterogeneity terms and through a possible direct effect of divorce on the migration hazard. The latter is the effect we are interested in. We consider both the incidence of divorce as well as its duration, and allow the impact to vary systematically with observed characteristics. In our empirical implementation these three aspects (incidence, duration, heterogeneity) are considered progressively. Thus the extended MPH model for the return hazard is

$$
\theta_{m}\left(t \mid t_{s}, x_{m}(t), z(t), v_{m}\right)=v_{m} \lambda_{m}(t) \exp \left(x_{m}(t) \beta_{x}^{m}+I_{d}(t)\left\{\gamma+\alpha\left(\delta_{d}(t)\right)+z(t) \phi\right\}\right) .
$$

The covariates $z$ in the (return) migration hazard are a subset of the time-varying characteristics of the migrants $x$. The duration impact, $\alpha$, is modelled by piecewise constant functions, so the effect of divorce is allowed to exhibit duration dependence.

The direct effect need to be distinguished from the correlated effect that arises from the correlation between the unobserved error terms $\left(v_{e}, v_{s}\right) \equiv v$ where $v$ is distributed according to some distribution function $G$.

\subsection{Endogeneity: Confounding unobservable heterogeneity}

We briefly discuss the important endogeneity issue. Due to dynamic sorting the distribution of $v_{s}$ among those who divorce at $t_{s}$ will differ from its population distribution. In particular, individuals with high $v_{s}$ will tend to divorce earlier than individuals with low $v_{s}$. If $v_{s}$ and $v_{m}$ are dependent, then the distribution $v_{m}$ for divorced migrants at a given time in the country will differ from the 
distribution of $v_{m}$ for migrants still married. Therefore, one cannot infer the effect of divorce on the return-migration from a comparison of the realised durations of those who divorced at $t_{s}$ with the rest of the population, because one would then mix the direct effect of divorce on the duration with the difference in the distribution of $v_{m}$ between these migrants. In this case $I_{d}(t)$ will be endogenous, and $T_{s}$ and $T_{m}$ should be modelled jointly to account for dependence of the unobserved heterogeneity terms. Therefore, we allow $v_{s}$ and $v_{m}$ to be correlated.

We adopt a commonly applied two-factor loading model with two independent fundamental factors $W_{1}$ and $W_{2}$, both having a discrete distribution on $(-1,1)$ with $p_{j}=\operatorname{Pr}\left(W_{j}=1\right)=\exp \left(\tilde{p}_{j}\right) /(1+$ $\left.\exp \left(\tilde{p}_{j}\right)\right)$. This implies that the unobserved heterogeneity is defined as

$$
v_{k}=\exp \left(\alpha_{k 1} W_{1}+\alpha_{k 2} W_{2}\right)
$$

with $k=\{s, m\}$. Let $W=\left(W_{1}, W_{2}\right)^{\prime}, v=\left(v_{s}, v_{m}\right)^{\prime}$ and $A$ be the matrix of factor loadings with rows $A_{k}=\left(\alpha_{k 1}, \alpha_{k 2}\right)$. Note that this two-factor model is very general as it allows for positive and negative correlations among the unobserved heterogeneity terms. The variance-covariance matrix of the unobserved heterogeneity terms is given by $\operatorname{Var}(\ln (v))=A \operatorname{Var}(W) A^{\prime}{ }^{2}$.

\subsection{Causal interpretation in a Timing of Events Model}

The "timing-of-events" method of Abbring and van den Berg (2003) implies that the full effect of divorce on the re-migration hazard, $\gamma+\alpha\left(\delta_{d}(t)\right)+z(t) \phi$ in our framework, has a causal interpretation. This requires that marriage and migration durations are modelled parametrically as mixed proportional hazards, as we have. Identification of the causal effect additionally requires that the so-called "no-anticipation"-assumption holds.

Denote by $t_{s}$ the time a divorce spell would start, and consider first the migration hazard at a time $t$ before the divorce. The (untestable) no-anticipation assumption requires that migrants do not anticipate the divorce by migrating before the anticipated event would occur. Note that leaving on the date the divorce occurs does not violate the identification assumption. Hence the migration hazard $\theta_{m}\left(t \mid t_{s}, x_{m}(t), v_{m}\right)$ is assumed to be affected only for $t>t_{s}$.

A possible threat to the validity of the no-anticipation assumption is that ending a relationship takes time and migrants may decide to leave before the marriage has officially terminated. For example, the migrant might be so unhappy in the current marriage that she prefers to return to her home country before separation. It is also possible that the legal procedure of separation has been initiated, but is yet not completed, nor registered before migration. In either case the existence of such a (latent) group of migrants would lead to an underestimate the causal effect of divorce on the migration hazard. We cannot deduce from our data whether many migrants leave in anticipation of a divorce. We are therefore cautious in using a casual interpretation of the effect of divorce on return migration. Still, the timing-of-events method corrects for possible endogeneity of the divorce process.

\subsection{Administrative Removal}

Before discussing the construction of the likelihood one data issue should be mentioned. Although in principle the exact date of emigration (and second and repeated immigration) is known, some migrants do not officially inform the authorities that they are about to leave the host country. However, all citizens (immigrants and natives) are required to register with their municipalities (this is a pre-requisite for many social services, and for tax-benefit matters). It is thus clear that any migrant who has no entries in the tax-benefit register and does not appear in the register of another municipality must have left the country. Only the exact date of the departure is unknown. Such non-compliers are periodically identified and removed from the registers by the authorities in a step labelled "administrative removal".

\footnotetext{
${ }^{2}$ One additional restriction is needed for identification. We let $\alpha_{m 2}=0$.
} 
We assume that the when a migrant is "administrative removed" and has "zero income at last observed time" implies that the migrant has left before the date the administrative removal is recorded, and after the last date of any observed change in the observed characteristics (e.g. labour market status, housing and marital status). Such limited information is equivalent to interval-censored data. For interval-censored data the exact timing of an event is unknown, but it is known that the duration ended in some period of time. If a migrant is administratively removed at duration $t_{a}$ and the last observed change for this migrant occurred at duration $t_{1}<t_{a}$, the contribution to the likelihood (of the out-migration) of this migrant is the probability of survival till $t_{1}$ times the probability that the migrant left the country between $t_{1}$ and $t_{a}$. The latter is equal to the survival from $t_{1}$ until $t_{a}$ given survival.

Let $a_{i}$ indicate whether the emigration of migrant $i$ was due to an administrative removal $\left(a_{i}=1\right)$. For an administratively removed migrant we introduce two different event dates: $t_{i}^{a}$ is the administrative removal date and $t_{i}^{1}<t_{i}^{a}$ is the date of the last recorded change in any of the characteristics of migrant $i$ before $t_{i}^{a}$.

\subsection{Likelihood Function}

We have data for $i=1, \ldots, n$ immigrants entering the Netherlands in our observation window. Let $K_{i}$ be the number of observed migration spells of individual $i$. The indicator $\Delta_{i}^{s}$ signals that marriage spell is uncensored and $\Delta_{i k}^{m}$ signals that $k^{\text {th }}$ migration spell is uncensored. Thus the likelihood contribution of migrant $i$ conditional on the unobserved heterogeneity $v=\left(v_{s}, v_{m}\right)$ is, in the light of the preceding discussions:

$$
\begin{aligned}
& L_{i}(v)=\left\{\left[\theta_{s}\left(t_{s i} \mid \cdot, v_{s}\right)^{\Delta_{i}^{s}} \exp \left(-\int_{0}^{t_{s i}} \theta_{s}\left(\tau \mid \cdot, v_{s}\right) d \tau\right)\right]^{\left(1-a_{i}\right)}\right. \\
& \cdot {\left.\left[\exp \left(-\int_{0}^{t_{s i}^{1}} \theta_{s}\left(\tau \mid \cdot, v_{s}\right) d \tau\right)-\exp \left(-\int_{0}^{t_{s i}^{a}} \theta_{s}\left(\tau \mid \cdot, v_{s}\right) d \tau\right)\right]^{a_{i}}\right\}^{I_{s}\left(t_{s i}^{-}\right)} } \\
& \times \prod_{k=1}^{K_{i}}\left[\theta_{m}\left(t_{i k} \mid \cdot, v_{m}\right)^{\Delta_{i k}^{m}} \exp \left(-\int_{0}^{t_{i k}} \theta_{m}\left(\tau \mid \cdot, v_{m}\right) d \tau\right)\right]^{\left(1-a_{i k}\right)} \\
& \cdot\left[\exp \left(-\int_{0}^{t_{i k}^{1}} \theta_{m}\left(\tau \mid \cdot, v_{m}\right) d \tau\right)-\exp \left(-\int_{0}^{t_{i k}^{a}} \theta_{m}\left(\tau \mid \cdot, v_{m}\right) d \tau\right)\right]^{a_{i k}}
\end{aligned}
$$

This likelihood naturally separates marriage and migration spells, and for each spell allows for censoring and administrative removal. To simplify notation, we have suppressed the dependence on observed characteristics in the hazard rates. $I_{s}\left(t_{s i}^{-}\right)$indicates that the migrant is married just before $t_{s i}$.

Integrating out the unobserved heterogeneity distribution we obtain the likelihood function

$$
L=\prod_{i=1}^{n} \iint L_{i}(v) d G\left(v_{s}, v_{m}\right)
$$

where $G\left(v_{s}, v_{m}\right)$ is the joint distribution of the unobserved heterogeneity terms implied by the discussion of $v_{k}$ given by equation (3).

\section{Data on recent family migrants to the Netherlands}

We have administrative data on all legal immigration by non-Dutch citizens to the Netherlands, who entered during our observation window of 1999-2007. These migrants are registered in the Central Register Foreigners (Centraal Register Vreemdelingen, CRV), using information from the Immigration 
Police (Vreemdelingen Politie) and the Immigration and Naturalization Service (Immigratie en Naturalisatie Dienst, IND). It is mandatory for every immigrant to notify the local population register immediately after the arrival in the Netherlands if (s)he intends to stay in for at least two thirds of the forthcoming six months.

In addition to the date of entry and exit, the administration also records the migration motive of the individual. Either the motive is coded according to the visa status of the immigrant, or the immigrant reports the motive upon registration in the population register. Statistics Netherlands distinguishes between the following motives: labour-migrants, family migrants, student immigrants, asylum seekers (and refugees), and immigrants for other reasons. Note that EU-citizens are required to register in The Netherlands, just as natives are. See Bijwaard (2010) for an extensive descriptive analysis of the various migration motives. ${ }^{3}$ In particular, about $25 \%$ of all non-Dutch immigrants in the age group 18-64 are family migrants. Given the subject of the current paper, we focus exclusively on these family migrants. As it is possible that the official migration motive does not always match with the true intention of the migrants, we further require that the immigrant be married in the Netherlands within three months of their entry.

This immigration register is linked by Statistics Netherlands to the Municipal Register of Population (Gemeentelijke Basisadministratie, GBA) and to their Social Statistical Database (SSD). The GBA contains basic demographic characteristics of the migrants, such as age, gender and country of origin. From the SSD we have information (on a monthly basis) on the marital status, labour market position, income, industry sector, housing and household situation. It is important to note that this information is only available for migrants during their stay in the Netherlands. When migrants leave any change in their marital or labour market status is unrecorded. However, when a migrant re-enters, the information on the previous stay(s) are also available.

Although in principle the exact date of emigration (and second and repeated immigration) is known, some migrants do not officially inform the authorities that they leave. The departure of these non-complying individuals is registered as an "administrative removal" after the authorities have assessed that the migrant has left the municipality without showing up in the files of another municipality in The Netherlands or as an emigrant. These administrative removals are included among emigration and they amount to around $22 \%$ of all emigrations. $73 \%$ of these administrative removed migrants have no observed income in the country. We conjecture that the majority of these migrants have left the country shortly after they stopped receiving income (either earnings or benefits). For those who still have income until they are administratively removed we assume that they left at that exact date. We have explicitly addressed the issue of administrative removals in the formulation of the likelihood, see Section 3.4 and 3.5.

In total we use a large panel of 100,392 family migrants, together having 102,663 migration spells (21,316 out-migrations), 103,545 marriage spells (9,127 divorces). For each migrant we derived, based on the country of birth, the human development index (HDI) produced by the United Nations Development Programme (UNDP). The size of the family migration population allows us to conduct separate analyses for distinc migrant groups. In particular, we distinguish three migrant groups according to the HDI of their country of birth: developed countries (DC), HDI $>0.7$, intermediate developed countries (IDC), HDI $0.582-0.7$ and less developed countries (LDC), HDI $<0.582$ UNDP (2011). These group boundaries are approximately equal to UNDP identifiers. More specific data information can be found in the appendix.

\subsection{Summary Statistics for Family Migrants}

In Table 1 we give some first insights in the migration and relationship dynamics of the family migrants. Note that the group of 'stayers' includes permanent migrants, and temporary migrants who have not yet returned. For all three groups the majority of family migrants are stayers, with migrants from

${ }^{3}$ Bijwaard et al. (2011) focus on labour migrants and the impact of labour market dynamics on their return. 
developed countries showing higher mobility. However, most of the migrants that return, do so within five years. Conditional on return migrants from less developed countries stay longer than the other migrants. These differences highlight already the importance of an analysis disaggregated by HDI. Figure 4.1 depicts the Kaplan Meier estimates of the return probabilities (=1- survival probabilities) by immigrant group. The return of family migrants from intermediate- and less-developed countries looks very similar. Migrants from developed countries are much prone to leave (more than twice as much) than migrants from the other groups. Overall, both Table 1 and Figure 4.1 highlight the importance of the temporary nature of family migration. Across all immigrant groups, a substantial proportion leave the Netherlands eventually.

Table 1: Descriptive Dynamics

\begin{tabular}{|c|c|c|c|c|}
\hline & All & $\mathrm{DC}$ & IDC & LDC \\
\hline $\mathrm{N}$ & 100,392 & 35,629 & 35,008 & 29,755 \\
\hline Stayer $^{1}$ & $79.3 \%$ & $64.9 \%$ & $86.7 \%$ & $87.7 \%$ \\
\hline multiple entry & $2.1 \%$ & $2.3 \%$ & $2.1 \%$ & $2.0 \%$ \\
\hline & \multicolumn{4}{|c|}{ Length of stay at return migration } \\
\hline$<1$ year & $16.5 \%$ & $17.1 \%$ & $15.5 \%$ & $16.2 \%$ \\
\hline $1-2$ years & $24.2 \%$ & $26.2 \%$ & $21.6 \%$ & $20.7 \%$ \\
\hline $2-3$ years & $19.3 \%$ & $21.3 \%$ & $17.9 \%$ & $14.4 \%$ \\
\hline $3-4$ years & $14.0 \%$ & $14.4 \%$ & $14.8 \%$ & $12.1 \%$ \\
\hline $4-5$ years & $10.4 \%$ & $9.6 \%$ & $11.4 \%$ & $11.8 \%$ \\
\hline$>5$ years & $15.5 \%$ & $11.5 \%$ & $18.9 \%$ & $24.8 \%$ \\
\hline average [months] & 34.5 & 32.1 & 37.0 & 39.4 \\
\hline & \multicolumn{4}{|c|}{ Relationship Dynamics } \\
\hline always married ${ }^{2}$ & $91.2 \%$ & $94.0 \%$ & $89.2 \%$ & $90.3 \%$ \\
\hline \multirow[t]{2}{*}{ once divorced } & $8.5 \%$ & $5.8 \%$ & $10.4 \%$ & $9.4 \%$ \\
\hline & \multicolumn{4}{|c|}{ Length of marriage at divorce } \\
\hline$<1$ year & $8.4 \%$ & $13.2 \%$ & $6.5 \%$ & $7.3 \%$ \\
\hline $1-2$ years & $11.9 \%$ & $12.8 \%$ & $12.8 \%$ & $10.1 \%$ \\
\hline $2-3$ years & $13.6 \%$ & $12.9 \%$ & $15.7 \%$ & $11.2 \%$ \\
\hline $3-4$ years & $21.1 \%$ & $17.7 \%$ & $22.2 \%$ & $22.1 \%$ \\
\hline $4-5$ years & $20.4 \%$ & $19.7 \%$ & $19.0 \%$ & $22.8 \%$ \\
\hline$>5$ years & $24.7 \%$ & $23.7 \%$ & $23.8 \%$ & $26.4 \%$ \\
\hline average [months] & 44.8 & 42.5 & 44.5 & 46.9 \\
\hline
\end{tabular}

Turning to the relationship dynamics, Table 1 reveals that migrants from developed countries, relative to the other groups, experience less marriage volatility. Figure 3 depicts the Kaplan Meier estimates of the probability to remain married by immigrant group. These probabilities are slightly higher for the migrants from developed countries and the lowest for migrants from intermediate developed countries. The gray line in the figure marks the 3 year limit when a family migrant gains more rights to stay. A very small increase in divorce is observed after that period which might indicate the end of marriage for convenience, a marriage which has as main purpose to obtain a living permission in the host country. However, this pattern is also visible for migrants from developed countries for whom this is not really an issue.

In Table 2 we condition on divorced migrants who leave. In line with the figures in Table 1, immigrants from developed countries have a lower incidence of divorce at the time of their departure 


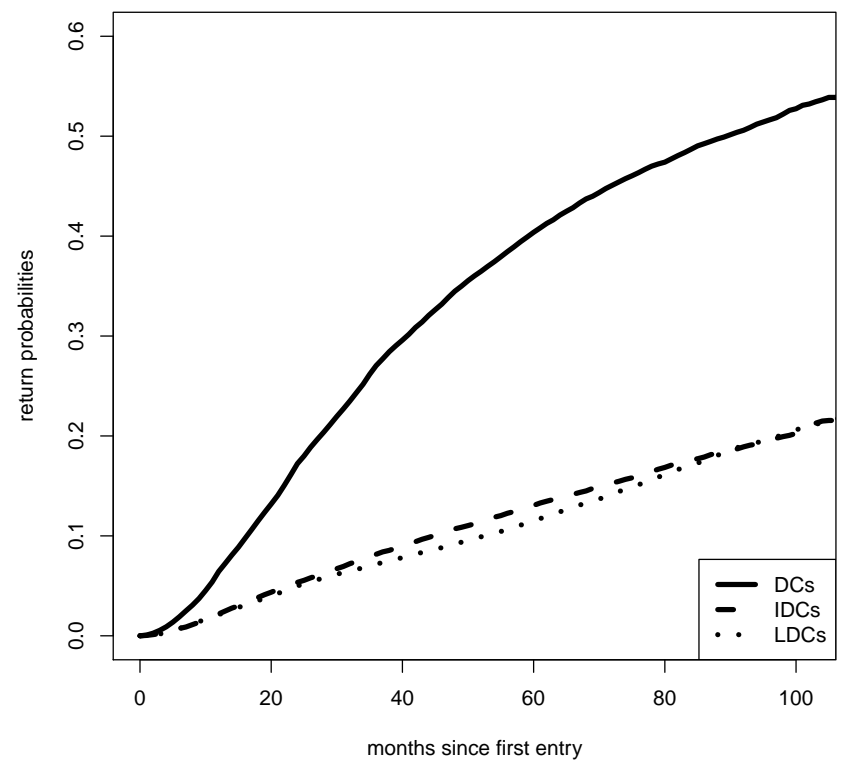

Figure 2: Kaplan Meier estimates of return probabilities

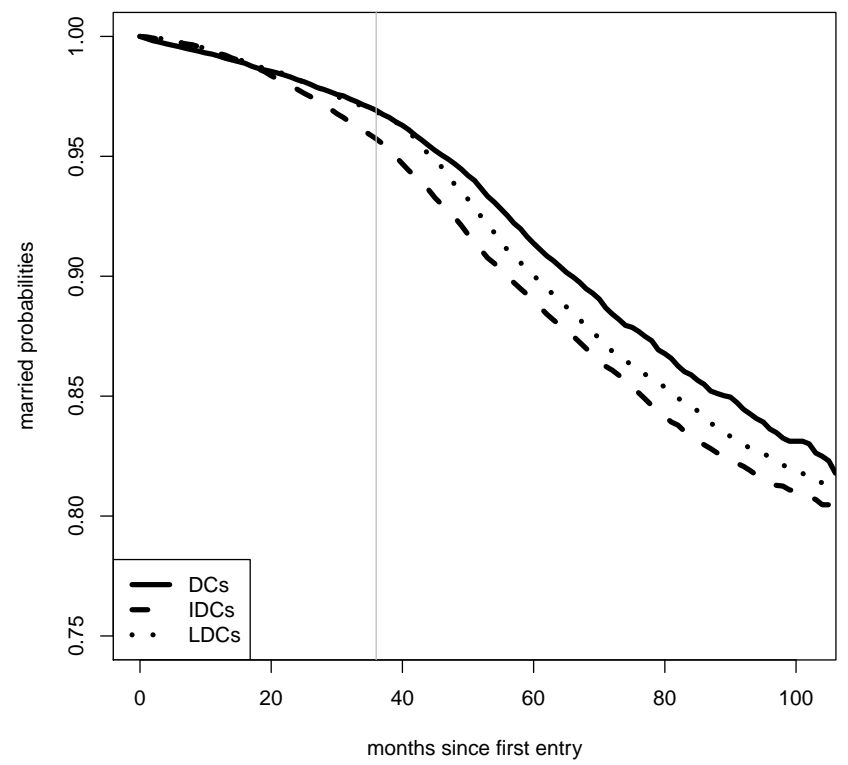

Figure 3: Kaplan Meier estimates of probability to remain married 
(3\%). These migrants have shorter divorce lengths when they leave. Migrants from intermediate developed countries have shorter preceding marriage spells when leaving while divorced. It should be noted, however, that the marriage duration is measured in time from entry into the Netherlands and that it is unknown how long the migrants have been married before entry.

Table 2: Descriptive Dynamics: Divorced immigrants who leave.

\begin{tabular}{l|llll}
\hline \hline & All & DC & IDC & LDC \\
\hline Divorced at emigration $^{1}$ & 5.8 & 2.9 & 10.0 & 10.1 \\
Mean \# of divorce spells & 1.016 & 1.014 & 1.03 & 1.022 \\
\hline & \multicolumn{4}{|c}{ Preceding marriage duration ${ }^{2}$} \\
$<1$ year & $14.6 \%$ & $12.2 \%$ & $16.4 \%$ & $14.6 \%$ \\
$1-2$ years & $23.1 \%$ & $24.7 \%$ & $22.6 \%$ & $22.2 \%$ \\
$2-3$ years & $18.0 \%$ & $19.7 \%$ & $20.1 \%$ & $14.6 \%$ \\
$3-4$ years & $17.7 \%$ & $16.0 \%$ & $19.3 \%$ & $17.2 \%$ \\
$4-5$ years & $13.3 \%$ & $16.3 \%$ & $8.1 \%$ & $17.0 \%$ \\
$>5$ years & $13.4 \%$ & $12.2 \%$ & $13.5 \%$ & $14.4 \%$ \\
average $[$ months] & 34.6 & 34.9 & 33.2 & 35.9 \\
\hline & \multicolumn{4}{|c}{ Current divorce duration 2} \\
$<2$ year & $71.2 \%$ & $73.4 \%$ & $70.1 \%$ & $70.2 \%$ \\
$2-3$ years & $13.5 \%$ & $11.9 \%$ & $14.1 \%$ & $14.4 \%$ \\
$>3$ years & $15.3 \%$ & $14.6 \%$ & $15.8 \%$ & $15.4 \%$ \\
average [months] & 18.9 & 18.1 & 19.3 & 19.2 \\
\hline \hline
\end{tabular}

\footnotetext{
1 Percentage of return migrants.

${ }^{2}$ Percentage of migrants returned while divorced.
} 


\section{$5 \quad$ Estimation results}

We consider three versions of our model given by equation (2). Recall that the causal impact of divorce on return migration hazard is given by $\gamma+\alpha\left(\delta_{d}(t)\right)+z(t) \phi$. In Model 1 the effect of divorce is assumed constant across time and migrants and thus given by $\gamma$ (with $\alpha \equiv \phi \equiv 0$ ). In Model 2 the covariate effect is still forced to zero, but the effects of sojourn times are allowed to exhibit duration dependence. This is implemented non-parametrically by modelling the sequence $\{\alpha\}$ as piece-wise constant functions. In Model 3 we further allow the effect to be heterogeneous across migrants in terms of $z$ which measure demographics and previous marriage history.

Although of secondary interest we first briefly discuss the effect of other covariates on the migration and divorce processes (based on the results of model 3), before we turn to the discussion of the effect of divorce on return migration.

\subsection{Migration process}

The covariates included in the migration hazard refer to individual demographic, individual labour market characteristics, characteristics of the country of birth and, the macro economic situation in the host country. We reckon that the demographic factors gender, age at entry, whether the migrant owns a house in the Netherlands and, number of children, influence the decision to return. Individual labour market characteristics include the employment status and monthly income. Religion and distance to the Netherlands of the country of birth capture the remaining heterogeneity within the migrant groups. Religious beliefs are very likely to have an effect on relationship transitions. Not only the beliefs of the individuals, but also the social environment in both the source and the host country may have an impact on relationship decisions and therefore also, indirectly, on (re-)migration. However, the religious background of the migrant is not registered in our data-set. We have constructed two dummies for groups of countries in which more than 80 percent of the population practises the same religion, Muslim or Christian. Medium distance countries have their center between 2,000 and 5,000 $\mathrm{km}$ from the center of the Netherlands, and long distance countries are more than $5,000 \mathrm{~km}$. Macroand business cycle factors are captured by the national unemployment rate (changing on a quarterly basis) and the national unemployment rate at the moment of entry. For developed countries a dummy for EU 15 countries is included, as migrants from those countries have freedom of movement. The baseline hazard has a piecewise constant form which changes with the year of stay.

Table 3 reports the estimated coefficients of those control variables on the migration hazards $\left(\beta_{x}^{m}\right.$ in (2)). Most of the control variables have a similar impact among the three migrant groups, such as female migrants are less likely to return and children reduce the migration mobility. Family migrants who enter the Netherlands at a young age are less likely to return. Finding a job or receiving benefits greatly reduces the chance of leaving. Migrants with a high income ( $>€ 4,000$ per month) are also more prone to leave. The estimated baseline hazard tells us that the hazard of leaving increases with the length of stay. DC-migrants from the EU 15 countries are more likely to leave. 
Table 3: Estimated effect of control variables on return migration hazards.

\begin{tabular}{l|cc|cc|cc}
\hline \hline \multirow{2}{*}{ Female } & \multicolumn{2}{|c|}{ DC } & \multicolumn{2}{c|}{ IDC } & \multicolumn{2}{c}{ LDC } \\
\# of children & $-0.139^{* *}$ & $(0.029)$ & $-0.605^{* *}$ & $(0.042)$ & $-0.626^{* *}$ & $(0.049)$ \\
aged 18-20 & $-0.286^{* *}$ & $(0.006)$ & $-0.466^{* *}$ & $(0.012)$ & $-0.366^{* *}$ & $(0.014)$ \\
aged 21-25 & $-0.746^{* *}$ & $(0.072)$ & $-0.851^{* *}$ & $(0.063)$ & $-0.468^{* *}$ & $(0.070)$ \\
aged 35-50 & $-0.311^{* *}$ & $(0.038)$ & $-0.433^{* *}$ & $(0.047)$ & $-0.205^{* *}$ & $(0.051)$ \\
aged > 50 & $0.067^{* *}$ & $(0.022)$ & 0.027 & $(0.045)$ & 0.001 & $(0.056)$ \\
No income & $-0.146^{* *}$ & $(0.039)$ & 0.064 & $(0.090)$ & -0.156 & $(0.152)$ \\
Low income & 0.009 & $(0.028)$ & $0.131^{* *}$ & $(0.041)$ & $-0.260^{* *}$ & $(0.047)$ \\
High income & $-0.362^{* *}$ & $(0.045)$ & -0.108 & $(0.072)$ & -0.012 & $(0.093)$ \\
house owned & $0.562^{* *}$ & $(0.065)$ & $0.685^{* *}$ & $(0.157)$ & $0.456^{+}$ & $(0.213)$ \\
employed & $-0.384^{* *}$ & $(0.021)$ & $-0.220^{* *}$ & $(0.038)$ & -0.086 & $(0.056)$ \\
Onbenefit & $-1.953^{* *}$ & $(0.111)$ & $-2.278^{* *}$ & $(0.256)$ & $-2.337^{* *}$ & $(0.332)$ \\
EU15 & $-1.761^{* *}$ & $(0.069)$ & $-1.637^{* *}$ & $(0.068)$ & $-1.743^{* *}$ & $(0.066)$ \\
Muslim Country & $0.689^{* *}$ & $(0.032)$ & - & & - & \\
Christian Country & $-0.335^{* *}$ & $(0.066)$ & $-0.431^{* *}$ & $(0.076)$ & $-0.464^{* *}$ & $(0.063)$ \\
medium distance & -0.006 & $(0.023)$ & $0.621^{* *}$ & $(0.061)$ & -0.018 & $(0.182)$ \\
long distance & $-0.363^{* *}$ & $(0.042)$ & $-0.357^{* *}$ & $(0.132)$ & $-0.948^{* *}$ & $(0.052)$ \\
Nat. Unemployment rate & $0.653^{* *}$ & $(0.029)$ & $-0.381^{* *}$ & $(0.146)$ & - & \\
Unemployment rate at entry & $-0.037^{* *}$ & $(0.010)$ & 0.025 & $(0.017)$ & $-0.051^{* *}$ & $(0.019)$ \\
repeated entry & $0.077^{* *}$ & $(0.012)$ & $0.047^{+}$ & $(0.022)$ & 0.025 & $(0.026)$ \\
1-2 years & 0.016 & $(0.082)$ & $0.337^{* *}$ & $(0.122)$ & 0.203 & $(0.148)$ \\
2-3 years & $0.929^{* *}$ & $(0.030)$ & $1.043^{* *}$ & $(0.055)$ & $0.892^{* *}$ & $(0.062)$ \\
3-4 years & $1.141^{* *}$ & $(0.036)$ & $1.197^{* *}$ & $(0.062)$ & $0.901^{* *}$ & $(0.073)$ \\
$>$ 4 years & $1.159^{* *}$ & $(0.044)$ & $1.292^{* *}$ & $(0.070)$ & $1.002^{* *}$ & $(0.082)$ \\
\hline \hline
\end{tabular}

Notes: SE in parentheses. ${ }^{+}: p<0.05$ and ${ }^{* *}: p<0.01$. Sector dummies while employed are also included 


\subsection{Divorce process}

The impact of the control variables on the divorce hazards, reported in Table 4, differ more among the migration groups than for the migration hazards. Not surprisingly, for all three groups children have a stabilizing effect on marriage and the effect is larger for less developed countries. When a migrant originates from a Muslim country (s)he is less likely to divorce. Migrants without income (thus, they financially depend on their spouse) are less prone to divorce. Migrants with a high income also have a more stable marriage. In economic downfalls the divorce rate increases. Migrants who receive benefits are more likely to divorce.

Table 4: Estimated effect of control variables on divorce hazards.

\begin{tabular}{l|cc|cc|cc}
\hline \hline & \multicolumn{2}{|c|}{ DC } & \multicolumn{2}{c|}{ IDC } & \multicolumn{2}{c}{ LDC } \\
Female & 0.012 & $(0.060)$ & $-0.378^{* *}$ & $(0.044)$ & -0.021 & $(0.051)$ \\
\# of children & $-0.289^{* *}$ & $(0.017)$ & $-0.463^{* *}$ & $(0.016)$ & $-0.784^{* *}$ & $(0.026)$ \\
aged 18-20 & -0.216 & $(0.115)$ & $-0.490^{* *}$ & $(0.062)$ & $-0.430^{* *}$ & $(0.078)$ \\
aged 21-25 & -0.024 & $(0.068)$ & $-0.476^{* *}$ & $(0.049)$ & $-0.226^{* *}$ & $(0.056)$ \\
aged 35-50 & $0.127^{+}$ & $(0.053)$ & $0.303^{* *}$ & $(0.051)$ & $0.197^{* *}$ & $(0.064)$ \\
aged > 50 & -0.134 & $(0.105)$ & 0.047 & $(0.112)$ & -0.252 & $(0.181)$ \\
No income & $-0.803^{* *}$ & $(0.060)$ & $-0.735^{* *}$ & $(0.049)$ & $-0.820^{* *}$ & $(0.057)$ \\
Low income & 0.102 & $(0.073)$ & -0.040 & $(0.051)$ & -0.026 & $(0.066)$ \\
High income & $-0.533^{* *}$ & $(0.171)$ & $-0.483^{+}$ & $(0.202)$ & -0.248 & $(0.254)$ \\
employed & 0.057 & $(0.063)$ & $0.193^{* *}$ & $(0.050)$ & $0.211^{* *}$ & $(0.063)$ \\
Onbenefit & $0.937^{* *}$ & $(0.072)$ & $0.806^{* *}$ & $(0.055)$ & $0.919^{* *}$ & $(0.060)$ \\
Muslim Country & $-0.215^{+}$ & $(0.097)$ & $-1.232^{* *}$ & $(0.103)$ & $-0.364^{* *}$ & $(0.099)$ \\
Christian Country & $0.208^{* *}$ & $(0.053)$ & $-1.055^{* *}$ & $(0.107)$ & 0.286 & $(0.283)$ \\
medium distance & $0.468^{* *}$ & $(0.065)$ & -0.140 & $(0.176)$ & $0.201^{* *}$ & $(0.073)$ \\
long distance & 0.056 & $(0.058)$ & $-0.651^{* *}$ & $(0.199)$ &. &. \\
Nat. Unemployment rate & $0.090^{* *}$ & $(0.024)$ & $0.068^{* *}$ & $(0.019)$ & $0.087^{* *}$ & $(0.022)$ \\
Unemployment rate at entry & 0.023 & $(0.032)$ & 0.008 & $(0.026)$ & 0.038 & $(0.031)$ \\
2-3 years & $0.255^{* *}$ & $(0.077)$ & $0.664^{* *}$ & $(0.058)$ & $0.432^{* *}$ & $(0.074)$ \\
3-4 years & $0.741^{* *}$ & $(0.075)$ & $1.240^{* *}$ & $(0.059)$ & $1.336^{* *}$ & $(0.066)$ \\
$>$ 4 years & $1.121^{* *}$ & $(0.077)$ & $1.476^{* *}$ & $(0.066)$ & $1.835^{* *}$ & $(0.069)$ \\
\hline \hline
\end{tabular}

Notes: SE in parentheses. ${ }^{+}: p<0.05$ and ${ }^{* *}: p<0.01$.

\subsection{The effect of divorce on re-migration}

Turning to the effect we are interested in and taking possible endogeneity into account. These effects of the divorce process on return are reported in Table 5. Only for migrants from developed countries divorce does not significantly increase return. A possible explanation for this insignificance is that these migrants are more prone to migrate anyway and their residence status does not depend on their marital status. Another explanation is that the rate of integration in the host country is related to the development of the source country. When a migrant is well integrated, she is more (financially) independent and therefore the 'need' for remigration will be less upon divorce. This is in line with the largest effect of divorce on return for migrants from less developed countries.

The results of Model 2 reveal that the effect exhibits duration dependence. For DC migrants divorce only has a a significant impact the first two years after divorce, while for LDC migrants the effect is the largest more than three years after divorce. For IDC migrants the picture is more heterogeneous, with a smaller effect two to three years after divorce. However, this patterns seems to be in line, again, with a relation between the effect of divorce and the integration rate. Further permitting the effect to vary across observed characteristics of the migrants (Model 3) makes the duration dependence 
insignificant. The impact of divorce on return is larger for young migrants (especially for IDC and LDC migrants) and for migrants with low income. Contrary to our intuition, male LDC migrants are much more effected by divorce than female migrants from these countries. The insignificance of the baseline effect implies that for the reference group of divorced migrants. i.e. female migrants with medium to high income, older than 25 and, a marriage duration less than three years, divorce has little impact on return.

Table 5: Estimated effect of divorce on return migration hazards.

\begin{tabular}{|c|c|c|c|}
\hline \multirow[b]{2}{*}{ Constant } & $\overline{\mathrm{DC}}$ & $\begin{array}{c}\text { IDC } \\
\text { Model } 1\end{array}$ & $\overline{\mathrm{LDC}}$ \\
\hline & $\begin{array}{c}0.164 \\
(0.097)\end{array}$ & $\begin{array}{l}0.354^{* *} \\
(0.078)\end{array}$ & $\begin{array}{c}0.798^{* *} \\
(0.083)\end{array}$ \\
\hline \multirow{3}{*}{$0-2$ years } & & Model 2 & \\
\hline & $0.213^{+}$ & $0.375^{* *}$ & $0.788^{* *}$ \\
\hline & $(0.094)$ & $(0.081)$ & $(0.088)$ \\
\hline \multirow[t]{2}{*}{ 2-3 years } & -0.081 & 0.253 & $0.731^{* *}$ \\
\hline & $(0.173)$ & $(0.142)$ & $(0.159)$ \\
\hline \multirow[t]{2}{*}{$>3$ years } & -0.033 & $0.304^{+}$ & $0.928^{* *}$ \\
\hline & $(0.170)$ & $(0.143)$ & $(0.160)$ \\
\hline \multirow{3}{*}{$0-2$ years } & & Model 3 & \\
\hline & 0.568 & -0.081 & -0.327 \\
\hline & $(0.416)$ & $(0.0273$ & $(0.328)$ \\
\hline \multirow[t]{2}{*}{ 2-3 years } & 0.316 & -0.170 & -0.351 \\
\hline & $(0.445)$ & $(0.301)$ & $(0.356)$ \\
\hline \multirow[t]{2}{*}{$>3$ years } & 0.494 & -0.083 & -0.184 \\
\hline & $(0.448)$ & $(0.302)$ & $(0.358)$ \\
\hline \multirow[t]{2}{*}{ Male } & 0.018 & 0.051 & $0.476^{* *}$ \\
\hline & $(0.133)$ & $(0.112)$ & $(0.136)$ \\
\hline \multirow[t]{2}{*}{ Low income } & 0.222 & $0.596^{* *}$ & $0.845^{* *}$ \\
\hline & $(0.130)$ & $(0.130)$ & $(0.159)$ \\
\hline \multirow[t]{2}{*}{ Aged 18-25 } & $0.707^{* *}$ & $0.871^{* *}$ & $0.770^{* *}$ \\
\hline & $(0.145)$ & $(0.111)$ & $(0.135)$ \\
\hline \multirow[t]{2}{*}{ EU15 } & -0.085 & - & - \\
\hline & $(0.136)$ & & \\
\hline \multirow[t]{2}{*}{$>3$ years together } & -0.459 & -0.073 & 0.342 \\
\hline & $(0.415)$ & $(0.276)$ & $(0.329)$ \\
\hline \multirow[t]{2}{*}{ 1-2 years in NL } & -0.611 & 0.013 & $0.897^{* *}$ \\
\hline & $(0.423)$ & $(0.286)$ & $(0.347)$ \\
\hline \multirow[t]{2}{*}{$2-3$ years in NL } & -0.514 & 0.097 & 0.389 \\
\hline & $(0.429)$ & $(0.293)$ & $(0.358)$ \\
\hline \multirow[t]{2}{*}{$3-4$ years in NL } & -0.108 & -0.008 & -0.043 \\
\hline & $(0.168)$ & $(0.154)$ & $(0.171)$ \\
\hline
\end{tabular}

Notes: SE in parentheses. ${ }^{+}: p<0.05$ and ${ }^{* *}: p<$ 0.01 .

Some marriages are relationships that serve the sole purpose of getting into the Netherlands. In such marriages, between a native and migrant, the partners stay together till the migrant has stayed long enough to gain a permanent residence permit, which is after three years of legal stay. Of course, we do not observe the motivation for the marriage. When such marriages of convenience are very common we expect to see an increase in the divorce rate and a decrease in the effect of divorce on the 
return hazard after three years of marriage. This pattern would be more prominent for LDC migrants, as it is more difficult for those migrants to obtain a living permission. From Table 4 we observe an increase in the divorce rate for all groups after three years of marriage, but this might also be for other reasons. To account for the marriages of convenience we allow the effect of divorce to depend on the time spent in the Netherlands at the moment of divorce. We find some indication of the existence of marriage of convenience for LDC migrants as the effect of divorce larger for migrants one to two years in the country.

\subsection{Quantification of Impacts}

Next we illustrate the impact of divorce patterns on migrants' return probabilities. We take the coefficient estimates of the return migration hazard models $\lambda_{m}$ and consider, for each immigrant group, several divorce profiles and its impact on the return probability. We abstract from observable individual heterogeneity and focus on the 'reference' immigrant by setting the covariate coefficients $\beta_{x}^{m}$ and $\phi$ in equation (2) to zero. The return probability $1-\operatorname{Pr}\left\{T_{m}>t\right\}$ where $\operatorname{Pr}\left\{T_{m}>t\right\}=$

$E_{v_{m}}\left\{\exp \left(-\int_{0}^{t} \theta_{m}(s) d s\right)\right\}$ is the the survival probability. The expectation is taken over unobserved heterogeneity $v_{m}$, recalling that $T_{m}$ is the time spend in the host country.

In order to assess the effect of the timing of a divorce, we consider divorces that start at 24,36 , and 48 months after entry into the Netherlands. Figure 4 displays the results. The figure clearly shows that divorce has a much larger impact on family migrants from LDC's. For those migrants the timing of divorce really matters. An early divorce, within 3 years of residence, has (in the long run) twice as much impact. 

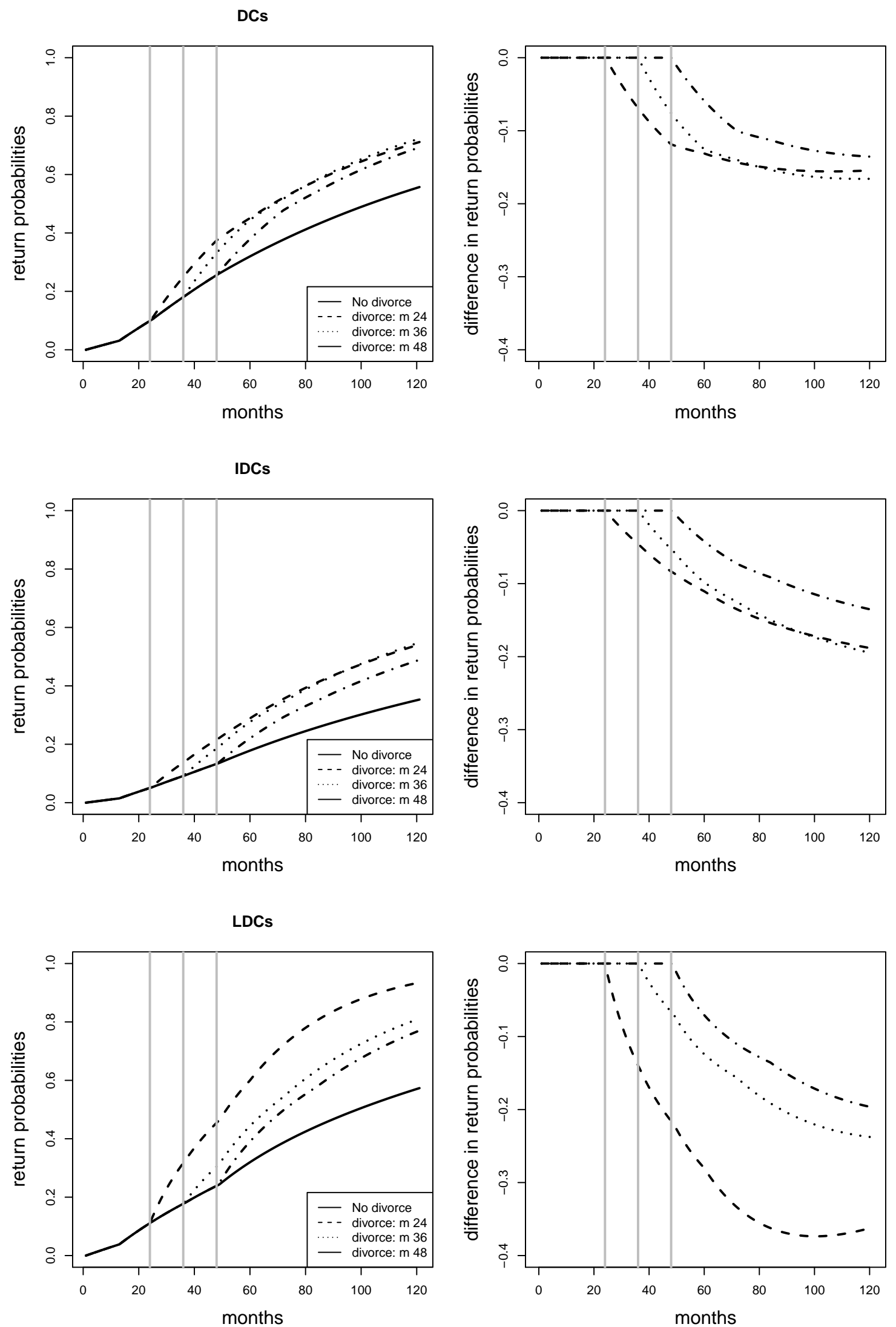

Figure 4: Effect of timing of divorce on return probabilities 


\subsection{Selectivity Bias}

We briefly illustrate the consequences of ignoring the endogeneity issue induced by the correlations between the unobservable heterogeneity terms $\left(v_{s}, v_{m}\right)$ given by distribution $G$. The 'timing-of-events' model nests the conventional (M)PH models for the return hazard. The PH model ignores unobservable heterogeneity altogether, $\theta_{m}^{P H}\left(t \mid t_{s}, x_{m}(t)\right)=\exp \left(x_{m}(t) \beta_{x}^{m}+I_{d}(t) \gamma\right)$, whereas the MPH model, $\theta_{m}^{M P H}\left(t \mid t_{s}, x_{m}(t), v_{m}\right)=v_{m} \theta_{m}^{P H}\left(t \mid t_{s}, x_{m}(t)\right)$ ignores the correlation between $\theta_{m}$ and $\theta_{s}$, see $(2)$. We quantify the resulting selectivity biases in terms of the estimated effects of divorce on the return migration hazards. For the sake of brevity, we illustrate the issue in the context of Model 1, i.e. the estimate of the constant effect given by $\gamma$. Table 6 reports the results.

The simple PH model already shows that for all migrant groups the incidence of a divorce significantly increases return probabilities. Extending this model to incorporate (uncorrelated) unobserved heterogeneity has only a small effect on the estimated effect. However, taking into account the correlated unobserved heterogeneity in the timing-of-events model has a substantial effect on the estimates. The estimated effect is typically smaller in magnitude than for both $\mathrm{PH}$ and MPH models. We conclude that ignoring the endogeneity issue would result in substantial selectivity biases. The bias of the uncorrelated models is induced by ignoring the positive correlation between the unobserved heterogeneity terms, $v_{m}$ and $v_{d}$. This positive selection (especially for IDC and LDC migrants) implies that migrants who are more prone to divorce ('risk lovers') are also more prone to migrate.

Table 6: The impact of the incidence of divorce on return-migration hazards

\begin{tabular}{l|ccc}
\hline \hline & DC & IDC & LDC \\
\hline PH-model & $0.262^{* *}$ & $1.036^{* *}$ & $1.017^{* *}$ \\
& $(0.054)$ & $(0.053)$ & $(0.060)$ \\
MPH-model & $0.301^{* *}$ & $1.067^{* *}$ & $1.078^{* *}$ \\
& $(0.059)$ & $(0.055)$ & $(0.065))$ \\
& & & \\
Timing of & 0.164 & $0.354^{* *}$ & $0.798^{* *}$ \\
Events model 1 & $(0.097)$ & $(0.078)$ & $(0.083)$ \\
\hline Corr $\left(v_{m}, v_{d}\right)$ & 0.321 & $0.999^{* *}$ & $0.543^{* *}$ \\
& $(0.239)$ & $(0.001)$ & $(0.061))$ \\
\hline \hline
\end{tabular}

${ }^{+} p<0.05$ and ${ }^{* *} p<0.01$

\section{Conclusion}

Most previous studies on migration have neglected the substantial extent of non-labour immigration. Indeed, family migrants constitute a large fraction of the inflow of immigrants. Although they are less prone to remigrate then labour migrants, a substantial proportion of them leaves the host country eventually. This is most apparent for family migrants from developed countries (DC). Within ten years more than fifty percent of those family migrants have left.

For family migrants their main migration motive is to live together with their (future) spouse. However, a substantial proportion of these marriages end in a divorce, just as with any other marriages in the Western world. If the relationship of the family migrant were to break up one or both partners would be likely to move and, therefore induce return migration.

Despite the importance of temporary immigration and marriage instability, the interdependence of divorce and immigration durations has received little attention in the empirical literature. In this paper we have addressed this gap using a unique Dutch administrative panel of the entire population of recent family immigrants in which we observe information on the timing of migration moves, timing of marital status changes, labour market changes and, income changes. The large size of the data enables 
us to estimate separate models for distinct immigrant groups, defined by the human development index of the UNDP, and we have shown the importance of controlling for observable migrant heterogeneity.

An empirical challenge arises from the potential correlation between the divorce process and the migration process which, if present and ignored, confounds the effect of divorce on return. The timing of events method enables us to estimate the effects of the timing and path of divorce on migration durations, while we controled for unobservable heterogeneity. Simpler (mixed) proportional hazard models which ignore correlations between divorce and migration processes are shown to exhibit substantial selection biases. We also discuss when the obtained effects of divorce have a causal interpretation.

Overall, we have found that, across all immigrant groups, divorce shorten the migration duration, with the largest impact for migrants from less developed countries. Most migrants from developed countries have more freedom of movement and depend less on their marital status for a valid living permission and are, therefore, less prone to leave the country after a divorce. Another reason why the effect of divorce is negatively related to the development of the country of birth is that migrants from more developed countries have a higher chance to integrate into the Dutch society and (the women) are therefore more independent after divorce. When we permit the effect to vary across observed characteristics of the migrants it becomes apparent that mainly young and low income migrants are affected. We also found some indication that marriage for convenience plays a role in the inflow of family migrants from less developed countries.

The impact of divorce on the duration of stay is qualified by an experiment which considers different timings of divorce. The experiment shows that the timing has a substantial impact on the magnitude of the effect of divorce of migrants from less developed countries. In particular, when such a migrant divorces after two years in the country the probability she leaves the country within ten years is almost twenty percent-point higher then when divorces after three or more years in the country. For migrants from the other immigrants groups the timing of divorce has much less impact.

Currently, we do not have spousal information, neither whether the partner is a native nor what the labour market situation of the partner is. An important avenue for further research is to view the behaviour of family migrants in a household perspective. With information on the characteristics and the behaviour of the partner linked to the individual migrant opens the opportunity to explore the interlinkage between the partners and its impact on migration behaviour.

\section{References}

Abbring, J. H. and G. J. van den Berg (2003). The non-parametric identification of treatment effects in duration models. Econometrica 71, 1491-1517.

Aydemir, A. (2011). Immigrant selection and short-term labor market outcomes by visa category. Journal of Population Economics 24, 451-475.

Aydemir, A. and C. Robinson (2008). Global labor markets, return and onward migration. Canadian Journal of Economics 41, 1285-1311.

Becker, G. S., E. M. Landes, and R. T. Michael (1977). An economic analysis of marital instability. Journal of Political Economy 85, 1141-1187.

Bijwaard, G. E. (2010). Immigrant migration dynamics model for The Netherlands. Journal of Population Economics 23, 1213-1247.

Bijwaard, G. E., C. Schluter, and J. Wahba (2011). The impact of labour market dynamics on the return-migration of immigrants. Discussion Paper No. 5722, IZA.

Borjas, G. J. (1999). The economic analysis of immigration. In O. Ashenfelter and D. Card (Eds.), Handbook of Labor Economics, Volume 3A, Chapter 28. Amsterdam: North-Holland.

Borjas, G. J. and B. Bratsberg (1996). Who leaves? The outmigration of the foreignborn. The Review of Economics and Statistics 78, 165-176. 
Boyle, P., T. Cooke, K. Halfacree, and D. Smith (2001). A cross-national comparison of the impact of family migration on women's employment status. Demography 38(2), 201-213.

Boyle, P. J., H. Kulu, T. Cooke, V. Gayle, and C. H. Mulder (2008). Moving and union dissolution. Demography 45, 209-222.

Djajić, S. (2008). Immigrant parents and children: An analysis of decicions related to return migration. Review of Development Economics 12, 469-485.

Dustmann, C. (1995). Return migration: The European experience. Economic Policy 22, 214-250.

Dustmann, C. and Y. Weiss (2007). Return migration: Theory and empirical evidence. British Journal of Industrial Relations 45, 236-256.

Edin, P.-A., R. J. Lalonde, and O. Åslund (2000). Emigration of immigrants and measures of immigrant assimilation: Evidence from Sweden. Swedish Economic Review 7, 163-204.

Flowerdew, R. and A. Al-Hamad (2004). The relationship between marriage, divorce and migration in a British data set. Journal of Ethnic and Migration Studies 30, 339-351.

Gibson, J. and D. McKenzie (2011). The microeconomic determinants of emigration and return migration of the best and brightest: Evidence from the Pacific. Journal of Development Economics 95, 18-29.

Hill, J. K. (1987). Immigrant decisions concerning durations of stay and migratory frequency. Journal of Development Economics 25, 221-234.

Hill, L. (2004). Connections between U.S. female migration and family formation and dissolution. Migraciones Internacionales 2(3), 60-82.

Jasso, G. and M. R. Rosenzweig (1982). Estimating the emigration rates of legal immigrants using administrative and survey data: The 1971 cohort of immigrants to the US. Demography 19, 279-290.

Jasso, G. and M. R. Rosenzweig (1995). Do immigrants screened for skills do better than family reunification immigrants? International Migration Review 29, 85-111.

Jensen, P. and P. J. Pedersen (2007). To stay or not to stay? out-migration of immigrants from Denmark. International Migration 45, 87-113.

Miller, P. (1999). Immigration policy and immigrant quality: The Australian points system. American Economic Review 89, 192-197.

Nivalainen, S. (2004). Determinants of family migration: Short moves vs. long moves. Journal of Population Economics 17, 157-175.

Rodriguez-Planas, N. and R. Vegas (2011). Moroccans' assimilation in Spain: Family-based versus labor-based migration. Middle East Development Journal 3, 119-139.

Sandell, S. (1977). Women and the economics of family migration. The Review of Economics and Statistics 59(4), 406-414.

UNDP (2011). Human Development Index. http://hdr.undp.org/en/media/HDR_2011_EN_ Table1.pdf.

Van den Berg, G. J. (2001). Duration models: Specification, identification, and multiple duration. In J. Heckman and E. Leamer (Eds.), Handbook of Econometrics, Volume V, Chapter 55, pp. 3381-3460. Amsterdam: North-Holland. 


\section{A Appendix}

Table 7 to 9 provide information on the migrant groups: the main countries, the HDI and the religion dummy.

Table 7: Main LDC Countries

\begin{tabular}{l|rrrrr}
\hline \hline LDC & $\mathrm{N}$ & $\%$ & HDI & Distance $(\mathrm{km})$ & Religion \\
\hline Morocco & 18185 & 62.54 & 0.582 & 2311 & Muslim \\
Iraq & 2197 & 7.56 & 0.573 & 3796 & Muslim \\
Afghanistan & 2152 & 7.40 & 0.398 & 5369 & Muslim \\
India & 1950 & 6.71 & 0.547 & 6368 & \\
Pakistan & 1188 & 4.09 & 0.504 & 5701 & \\
Nigeria & 785 & 2.70 & 0.459 & 5090 & Muslim \\
Ghana & 579 & 1.99 & 0.541 & 5210 & \\
Somalia & 532 & 1.83 & 0.316 & 6717 & Muslim \\
Sudan & 471 & 1.62 & 0.408 & 4758 & Muslim \\
Ethiopia & 317 & 1.09 & 0.363 & 5693 & \\
Bangladesh & 176 & 0.61 & 0.5 & 7649 & \\
Cameroon & 151 & 0.52 & 0.482 & 5412 & \\
Senegal & 141 & 0.48 & 0.459 & 4624 & \\
Gambia & 130 & 0.45 & 0.42 & 4719 & \\
Burundi & 122 & 0.42 & 0.316 & 6591 & \\
\hline Total & 29076 & & & & \\
\hline \hline
\end{tabular}

Table 8: Main IDC Countries

\begin{tabular}{l|rrrrr}
\hline \hline IDC & $\mathrm{N}$ & $\%$ & HDI & Distance $(\mathrm{km})$ & Religion \\
\hline Turkey & 20091 & 57.90 & 0.699 & 2215 & Muslim \\
Surinam & 2942 & 8.48 & 0.68 & 7495 & \\
China & 2393 & 6.90 & 0.687 & 7844 & \\
Indonesia & 2090 & 6.02 & 0.617 & 7055 & Muslim \\
Egypt & 1724 & 4.97 & 0.644 & 3291 & Muslim \\
Thailand & 1014 & 2.92 & 0.682 & 9179 & \\
Philippines & 1014 & 2.92 & 0.644 & 10407 & Christian \\
Southern Africa & 936 & 2.70 & 0.619 & 9648 & \\
\hline Total & 33909 & & & & \\
\hline \hline
\end{tabular}


Table 9: DC Country Specific Information

\begin{tabular}{l|rrrrr}
\hline \hline DC & $\mathrm{N}$ & $\%$ & $\mathrm{HDI}$ & Distance $(\mathrm{km})$ & Religion \\
\hline Poland & 4158 & 11.98 & 0.813 & 1098 & Christian \\
USA & 3407 & 9.82 & 0.91 & 6206 & \\
Russia & 3275 & 9.44 & 0.755 & 2157 & \\
Japan & 2435 & 7.02 & 0.901 & 9227 & \\
Germany & 2371 & 6.83 & 0.905 & 576 & \\
UK & 2291 & 6.60 & 0.863 & 356 & \\
Yugoslavia & 2229 & 6.42 & 0.728 & 1200 & \\
Iran & 1410 & 4.06 & 0.707 & 4027 & Muslim \\
Brazil & 1084 & 3.12 & 0.718 & 9091 & Christian \\
Romania & 1025 & 2.95 & 0.781 & 1800 & Christian \\
France & 933 & 2.69 & 0.884 & 429 & \\
Belgium & 761 & 2.19 & 0.886 & 171 & \\
\hline Total & 35269 & & & & \\
\hline \hline
\end{tabular}

Table 10: Mean values of included covariates by migrant-group (at entry).

\begin{tabular}{l|ccc}
\hline \hline & DC & IDC & LDC \\
Female & 0.838 & 0.668 & 0.696 \\
\# of children & 0.575 & 0.461 & 0.620 \\
aged 18-20 & 0.031 & 0.151 & 0.119 \\
aged 21-24 & 0.111 & 0.253 & 0.233 \\
aged 25-34 & 0.459 & 0.401 & 0.466 \\
aged 35-50 & 0.335 & 0.173 & 0.164 \\
aged $>50$ & 0.064 & 0.023 & 0.017 \\
\hline Low income $(<€ 2000)$ & 0.067 & 0.040 & 0.045 \\
Medium income $(€ 2000-€ 4000)$ & 0.920 & 0.958 & 0.953 \\
High income $(>€ 4000)$ & 0.012 & 0.001 & 0.001 \\
house owned & 0.335 & 0.238 & 0.101 \\
employed & 0.088 & 0.035 & 0.027 \\
\hline EU15 & 0.237 & - & - \\
Muslim Country & 0.052 & 0.729 & 0.875 \\
Christian Country & 0.384 & 0.056 & 0.006 \\
short distance & 0.492 & 0.012 & 0 \\
medium distance & 0.163 & 0.656 & 0.710 \\
long distance & 0.345 & 0.332 & 0.290 \\
$\mathrm{~N}$ & 35,629 & 35,008 & 29,755 \\
\hline \hline
\end{tabular}

